Short Communication

\title{
Evaluation of Corrosion Inhibition Effect of white mulberry leaves extract on HRB500 Carbon Steel in Alkaline Chloride Solutions
}

\author{
Baixiao Tang \\ Engineering Management, AnKang University, AnKang city, Shaanxi Province 725000, China \\ E-mail: baixiaotang2019@126.com
}

doi: $10.20964 / 2020.12 .11$

Received: 25 April 2020 / Accepted: 26 May 2020 / Published: 31 October 2020

Corrosion resistance of HRB500 carbon steel in alkaline environment with various inhibitor and $\mathrm{NaCl}$ concentrations were investigated using electrochemical impedance spectroscopy (EIS), potentiodynamic polarization, and scanning electron microscope. The inhibition effect of white mulberry leaves extract (WMLE) on carbon steels in alkaline media were studied. Results revealed that inhibitor and chloride values played a significant role in the formation of protective passive layers on the steel surface. The EIS analysis is in agreement with the best-fit results for double-layer capacitance of solution-steel interface which were steadily increased over $126.5 \mu \mathrm{Fcm}^{-2}$ with $4 \mathrm{wt} \% \mathrm{NaCl}$ in the alkaline solution, indicating that produced corrosion can occur on the steel surface. Results achieved from electrochemical analysis indicated that a high value of inhibition efficiency $(88 \%)$ was obtained in the presence of 400 $\mathrm{mg} / \mathrm{L}$ WMLE at room temperature.

Keywords: Green corrosion inhibitor; Alkaline environment; Electrochemical corrosion behavior; Electrochemical impedance spectroscopy

\section{$\underline{\text { FULL TEXT }}$}

(C) 2020 The Authors. Published by ESG (www.electrochemsci.org). This article is an open access article distributed under the terms and conditions of the Creative Commons Attribution license (http://creativecommons.org/licenses/by/4.0/). 